Orange Journal / Volumen 2 Número 3/ Enero - Junio 2020

DOI: https://doi.org/10.46502/issn.2710-995X/2020.3.01

\title{
Educação em saúde na perspectiva do enfermeiro da estratégia saúde da família de um município da fronteira do Brasil
}

\section{La educación en salud desde la perspectiva de la enfermera de la estrategia de salud familiar de un municipio de la frontera de Brasil}

\section{Resumo}

A educação em saúde é um instrumento facilitador para a capacitação da comunidade, e o mesmo contribui para a promoção de saúde. Desta forma, é necessário que trabalhadores de saúde e usuários estabeleçam uma relação dialógica pautada na escuta terapêutica, bem como respeito, valorização das experiências, história de vida e da visão de mundo. Este estudo caracterizar-se a educação em saúde na perspectiva do enfermeiro de Estratégia Saúde da Família no Município de Oiapoque. Tratou-se de uma pesquisa de campo de natureza básica do tipo exploratório-descritivo, com abordagem qualitativa, através da técnica de análise discursiva de texto mediante aplicação de questionário estruturado composto por questões abertas, a serem aplicadas com os enfermeiros(as) que trabalham nas Unidades Básicas de Saúde do Município de Oiapoque, e que atendem o programa Estratégia Saúde da Família. O Campo de ação foram as cinco Unidades Básicas da Saúde localizadas no município de Oiapoque. Foi analisado sob a ótica de três temáticas contadas nas falas dos entrevistados e dividido em categorias. A Categoria I: Analisou a concepção de educação em saúde como uma importante ferramenta de prevenção. A Categoria II: Identificou as ações de educação em saúde desenvolvidas no cotidiano da Estratégia de Saúde da Família. Na Categoria III: Foram listados os fatores que dificultam a realização da educação em saúde. Este estudo procurou contribuir com o fortalecimento

\footnotetext{
1 Enfermagem, Docente da Universidade Federal do Amapá - Campus Binacional do Oiapoque. Amapá, Brasil. 2 Acadêmica de enfermagem, Macapá, Amapá - Campus Binacional do Oiapoque. Amapá, Brasil.

3 Enfermagem, Docente da Universidade Federal do Amapá - Campus Binacional do Oiapoque. Amapá, Brasil.

4 Professor Assistente, Universidade Federal do Amapá - Campus Binacional do Oiapoque. Amapá, Brasil/Académico do Centro Universitário Leonardo Da Vinci - UNIASSELVI/Académico da Faculdad e de Venda Nova do Imigrante - FAVENI.
} 


\section{ORANGE JOURNAL}

das ações educativas em saúde, através da valorização destas, como instrumento de prevenção e promoção da saúde, bem como da autonomia dos indivíduos envolvidos neste processo para despertar o interesse por essa temática por parte dos acadêmicos da área da saúde e dos profissionais enfermeiros que atuam na área, tendo em vista a grande relevância e a necessidade de discutir a educação em saúde sobre uma nova perspectiva.

Palavras-chave: Educação em Saúde; Promoção da Saúde; Estratégia Saúde da Família.

\section{Resumen}

La educación para la salud es una herramienta facilitadora para el empoderamiento de la comunidad y contribuye a la promoción de la salud. Así, es necesario que los trabajadores de la salud y los usuarios establezcan una relación dialógica basada en la escucha terapéutica, así como el respeto, la valoración de las experiencias, la historia de vida y la cosmovisión. Este estudio se caracteriza como educación para la salud desde la perspectiva de la enfermera de la Estrategia Salud de la Familia en la ciudad de Oiapoque. Se trató de una investigación de campo básica de tipo exploratorio-descriptivo, con enfoque cualitativo, mediante la técnica de análisis de texto discursivo y con la aplicación de un cuestionario estructurado compuesto por preguntas abiertas. Se aplicó con enfermeras que laboraban en las Unidades Básicas de Salud del Municipio de Oiapoque, que pertenecían al programa Estrategia Salud de la Familia. El campo de acción fueron las cinco Unidades Básicas de Salud ubicadas en el municipio de Oiapoque. Se analizó desde la perspectiva de tres temas contabilizados en las declaraciones de los entrevistados y divididos en categorías. La Categoría I: Analizó el concepto de educación para la salud como una importante herramienta de prevención. La Categoría II: Identificó las acciones de educación en salud desarrolladas en la vida diaria de la Estrategia de Salud de la Familia. Y en la Categoría III: Se enumeraron los factores que dificultaban la realización para llevar a cabo la educación para la salud. Este estudio pretendió contribuir con el fortalecimiento de las acciones educativas en salud, a través de la valorización de estas, como instrumento de prevención y promoción de la salud, así como a la autonomía de los individuos involucrados en este proceso para despertar el interés en esta temática por parte de los académicos de las carreras de la salud y de los profesionales de enfermería que laboran en el área, ante la gran relevancia y necesidad de discutir la educación en salud desde una nueva perspectiva.

Palabras clave: Educación para la salud; Promoción de la salud; Estrategia de salud familiar.

\section{Introdução}

O Ministério da Saúde implantou oficialmente em 1994, como um programa a Estratégia saúde da Família (ESF), mas só em 1997, que ela foi elevada à condição de estratégia de organização do modelo assistencial. Ela se define como um conjunto de ações de reabilitação, prevenção e promoção da saúde, centrada na família e na comunidade à começar pelo trabalho da equipe interdisciplinar na área da Atenção Primária à Saúde. A ESF é uma das principais propostas do Ministério da Saúde. Um modelo de assistência que busca reorganizar a atenção básica a partir dos princípios do SUS. Um dos papeis 
fundamentais da ESF é o estabelecimento de vínculos, bem como a coordenação do cuidado e ampliação do trabalho a partir da associação das características sociais, culturais, econômicas e epidemiológicas do território às demandas e necessidades em saúde da população (Barra, 2013; Malta et al, 2016)

Dentre as atribuições específicas do profissional enfermeiro estão: supervisionar, coordenar e realizar atividades de educação permanente dos Agentes Comunitários de Saúde (ACS), e da equipe de enfermagem. Pois o mesmo se depara constantemente com situações referente à educação, tanto da comunidade como da capacitação dos profissionais sob sua supervisão. Por isso supervisionar e educar os ACS é um dos importantes papeis do enfermeiro, pois desta forma gera novas competências ao trabalho deste grupo, somando novos conhecimentos e fortalecendo as experiências, para que juntamente possam enfrentar os desafios, permitindo a população uma melhor qualidade de vida (Bassoto e Radicchi, 2012). A educação em saúde é um instrumento facilitador para a capacitação da comunidade, e o mesmo contribui para a promoção de saúde. Desta forma é necessário que trabalhadores de saúde e usuários estabeleçam uma relação dialógica pautada na escuta terapêutica, bem como respeito, valorização das experiências, história de vida e da visão de mundo. E para que estas ações sejam desenvolvidas, é necessário que os trabalhadores de saúde conheçam as práticas educativas, além do mais é essencial conhecer o olhar do outro, para que haja essa interação e reconstruir coletivamente saberes e práticas cotidianas (Cervera, Parreira, e Goulart, 2011).

Diante disso, tal estudo se justifica pelo fato dessa ação apresentar-se como uma das bases das políticas públicas de saúde que mais se destaca como estratégia para a transformação da qualidade de vida da população, surge a necessidade de abordar acerca da educação em saúde feita pelo enfermeiro frente à ESF.

A motivação dessa pesquisa foi conhecer e relatar a experiência vivenciada pelo Enfermeiro dentro da ESF, onde foi possível dar mérito às suas opiniões, conhecimentos, dificuldades e perspectivas advindas de sua própria forma de educar em saúde, via essencial para a mudança do modelo biomédico, hospitalocêntrico e curativista de assistência atual, examinando ainda, sua contribuição como agente facilitador de mudança para a consolidação de um modelo de atenção integral e de vigilância em saúde como a ESF.

Diante disso, surgiu o problema da pesquisa: qual é a percepção crítica do enfermeiro sobre sua própria forma de educar em saúde? A partir do qual obtiveram-se as seguintes questões norteadoras, a saber: Qual a concepção do enfermeiro da ESF acerca da educação em saúde? Como o enfermeiro trabalha ou desenvolve a educação em saúde? Quais as dificuldades que o enfermeiro da ESF encontra para realizar ações de educação em saúde no município de Oiapoque?

\section{Metodologia}

Trata-se de um estudo de natureza básica do tipo exploratório-descritivo, com abordagem qualitativa, através da técnica de análise discursiva de texto mediante aplicação de 


\section{ORANGE JOURNAL}

questionário estruturado composto por questões abertas. Com as enfermeiras que trabalham nas Unidades Básicas de Saúde (UBS) que possuem a ESF.

Esta pesquisa foi realizada com as enfermeiras da ESF do Município de Oiapoque. Neste município há 5 (cinco) Unidades Básicas de Saúde (UBS), todas desenvolvem a ESF, sendo elas: UBS do Planalto, UBS Nova Esperança, UBS Clevelândia do Norte, UBS Infraero e UBS Julieta Palmerim, todas ficam localizadas na zona urbana. A coleta de dados foi realizada no mês de setembro a novembro de 2020, observada as recomendações e aprovação deste projeto de pesquisa por um comitê de ética com número do parecer: 2.322.920 do Comitê de Ética da UNIFAP vinculado a Plataforma Brasil. O Instrumento de Coleta de Dados - ICD (Anexo 1), as entrevistas foram realizadas através de um questionário contendo 6 (seis) perguntas abertas, sendo gravadas por meio de um gravador digital. Os enfermeiros foram contatados e que desejem participar voluntariamente da pesquisa foi agendado dia e a hora conforme disponibilidade de cada um. O encontro ocorreu na UBS onde os mesmos desenvolvem suas atividades. Para se coletar os dados, primeiramente foi para lançado o convite para participação do estudo, seguido da apresentação e explicação verbal dos objetivos da pesquisa aos participantes, os quais assinaram o TCLE. Logo após, foi realizada a pesquisa de campo e se, utilizando o ICD que foi entregue e foi preenchido no mesmo instante, observando a viabilidade de tempo, e de forma individual, durou em média 10 minutos. No entanto, houve a necessidade de mudança na conduta da coleta devida o pouco tempo para responder aos questionamentos os participantes, devido a isso, utilizou-se um gravador de voz para que não se perdesse nenhuma informação durante a coleta e com a prévia autorização dos indivíduos participantes do estudo. Os dados resultantes da pesquisa de campo foram analisados tendo como referência (Bardin, 2016) com enfoque na análise de conteúdo, o qual aponta como pilares a fase da descrição ou preparação do material, inferência ou dedução e a interpretação. Sendo assim, os principais pontos da pró-análise são a leitura meio dispersa (primeiro contato com os textos), a escolha dos documentos que no caso são os relatos transcritos e laboração dos indicadores, ou seja, a frequência de aparecimento desse indicador (Bardin, Reto, e Pinheiro, 2000). Para tratamento dos dados a técnica da análise temática ou categorial foi utilizada e, de acordo com (Santos, 2012), baseia-se em operações de desmembramento do texto em unidades, ou seja, descobrir os diferentes núcleos de sentido que constituem a comunicação, e posteriormente, realizar o seu reagrupamento em classes ou categorias (Santos, 2012). As respostas das entrevistas aplicadas as enfermeiras da ESF foram separadas e analisadas através da metodologia de (Bardin, 2016) o qual utiliza a análise de conteúdo cujas fases são: $1^{\circ}$ fase: transcrever literalmente as respostas encontradas; $2^{\circ}$ fase: organizar o material coletado e fazer uma leitura "flutuante", para obter uma categorização dos dados obtidos; $3^{\circ}$ fase: codificar os dados obtidos, transformando os dados brutos através de agregações (escolha das categorias) para atingir uma representação do conteúdo, ou de sua expressão, suscetível de esclarecer as características dos dados coletados; $4^{\circ}$ fase: distribuir componentes dos dados analisados em categorias, classificando-os por diferenciação e por reagrupamentos em torno de critério previamente, ou não, estabelecidos. 


\section{Resultados e discussão}

O perfil das participantes e a análise foram realizadas sob a ótica de três temáticas principais contadas nas falas dos entrevistados: I: Concepção de educação em saúde. II: As ações de educação em saúde desenvolvidas no cotidiano da ESF. III: Fatores que dificultam a realização da educação em saúde. Os profissionais entrevistados foram nomeados com a sigla Enf. e o número de participantes foram 4 (quatro).

\section{Tabela I.}

Caracterização do perfil das enfermeiras que trabalham na Estratégia de Saúde da Família, Brasil, 2020.

\begin{tabular}{|c|c|c|c|c|c|}
\hline Identificação & Sexo & Idade & $\begin{array}{c}\text { Tempo de } \\
\text { Graduação }\end{array}$ & $\begin{array}{l}\text { Tempo } \\
\text { de } \\
\text { atuação } \\
\text { ESF }\end{array}$ & Especialidade \\
\hline Enf. 1 & $\mathrm{~F}$ & $\begin{array}{c}41 \\
\text { anos }\end{array}$ & 7 anos & 7 anos & Saúde pública e Saúde da Família \\
\hline Enf. 2 & $\mathrm{~F}$ & $\begin{array}{c}30 \\
\text { anos }\end{array}$ & 2 anos & 1 ano & Não tem \\
\hline Enf. 3 & $\mathrm{~F}$ & $\begin{array}{c}27 \\
\text { anos }\end{array}$ & 10 meses & 7 meses & $\begin{array}{c}\text { Cursando Saúde Pública e Saúde } \\
\text { do trabalhador }\end{array}$ \\
\hline Enf. 4 & $\mathrm{~F}$ & $\begin{array}{c}45 \\
\text { anos }\end{array}$ & 12 anos & 11 anos & Saúde da Família \\
\hline Enf. 5 & $\mathrm{~F}$ & $\begin{array}{c}28 \\
\text { anos }\end{array}$ & 2 anos & 2 anos & Não tem \\
\hline
\end{tabular}

Fonte: Dados primários desta pesquisa.

O perfil socioeconômico traçado a partir do levantamento dos dados através das informações das entrevistadas segue da seguinte forma: no que concerne ao item idade, os profissionais entrevistados estão na faixa etária entre 27 a 45 anos e percebe-se que $100 \%$ dos entrevistados eram do sexo feminino (Ojeda et al, 2008) discute os saberes e papeis de gênero construídos historicamente na sociedade brasileira que influenciam na escolha da profissão, este o fato aliado ao número de mulheres que ingressam atualmente nos cursos de graduação também favorecem uma crescente para que profissionais de enfermagem em sua maioria sejam do sexo feminino.

Villela et al. (2011) apontam a questão do gênero como um fator para a predominância de mulheres como profissionais de enfermagem, que estas desenvolvem suas atividades laborais vinculadas as suas experiências de vida. Deste modo, sendo o trabalho da enfermagem, nesta perspectiva, associado aos cuidados prestados por mulheres desde os primórdios.

Quanto à especialidade, três (3) afirmaram ter realizado pelo menos uma especialização e duas (2) afirmou não possuir especialidade. Ao perguntarmos às entrevistadas sobre a quanto tempo que concretizaram suas graduações de enfermagem duas (3) relataram que terminaram seus estudos de graduação no período decorrido de 10 meses a 02 anos sendo que duas das entrevistadas que não possui especialidade são recém-formadas no período 


\section{ORANGE JOURNAL}

de 10 meses e ainda não aderiu nenhuma especialidade devido afirmarem a falta de tempo para voltar-se aos estudos, 50\% afirmaram estarem formadas no período de 7 a 12 anos de graduação e já possuírem especialidade em Saúde da Família.

De acordo com Regis e Batista (2015); Souto et al (2020) o profissional que atua na área da Saúde Coletiva precisa obter habilidades e competências para realização de atividades distintas, dentre elas, gerência, assistência e de educação em saúde afim de contribuir para consolidação da ESF. Neste sentido é necessário que o profissional que atua na ESF tenha conhecimento científico para o desenvolvimento eficaz de tais competências.

Em relação ao tempo de atuação na ESF, não houve uma destoou das respostas anteriores, representando níveis parecidos com o tempo formação e o tempo de trabalho, no qual ficou dividido da seguinte forma: três (3) das participantes afirmaram estarem trabalhando na ESF a (7 meses a 1 ano) e (2) de ( 7 anos a 11 anos).

\section{Temática I: Concepção de educação em saúde}

A primeira temática diz respeito à concepção de educação em saúde. Na qual, podemos analisar pelas entrevistas realizadas que esta é uma importante ferramenta e que através dela pode-se conscientizar e orientar a população para prevenção de doenças e agravos.

A educação em saúde é um instrumento de suma importância, e de acordo com (Oliveira e Gonçalves, 2004) “(...) pela sua magnitude, deve ser entendida como uma importante vertente à prevenção, e que na prática deve estar preocupada com a melhoria das condições de vida e de saúde das populações." No entanto, para que se alcance um nível adequado de saúde, é preciso que as pessoas saibam identificar e satisfazer as necessidades básicas, dentre elas estão mudanças de comportamento, práticas e atitudes, além de dispor dos meios necessários à operacionalização dessas mudanças. Portanto, a educação em saúde neste ponto de vista colabora para que as pessoas tenham autonomia para identificar e utilizar as formas e os meios para preservar e melhorar a sua vida (Oliveira e Gonçalves, 2004).

Neste sentido, o enfermeiro possui um papel fundamental nesta prática, tendo em vista que através de seu planejamento e execução de suas ações em educação em saúde poderá contribuir de maneira significativa para o fortalecimento da autonomia do indivíduo no cuidado da sua saúde, bem como, no cuidado dos seus familiares.

(Horta, 1974) atribui a função do enfermeiro à uma ciência e a arte de cuidar do ser humano, especialmente no que diz respeito aos cuidados prestados as necessidades humanas básicas. Contudo, torná-lo independente da assistência prestada por intermédio da educação, desenvolvendo sua capacidade de cuidar da sua saúde com o auxílio dos profissionais da saúde. Conforme os relatos das entrevistadas, a educação em saúde contribui como uma importante ferramenta de prevenção.

"Bom, acredito que a educação em saúde, seja uma ferramenta importante, pra conscientizar a população e orientar a população sobre...principalmente sobre prevenção” (Enf. 3) 
"Mas quando você tá ensinando o paciente. (...), você tá trabalhando a prevenção. Então eu vejo assim como uma, uma arma, que a gente tem na prevenção de saúde. Então é esse, é um, tipo a maneira que eu vejo a educação em saúde" (Enf. 2)

"É dar informações corretas pra que a família venha prevenir certas doenças, tá? que pode ser evitadas." (Enf. 5)

De acordo, com Vasconcelos et al, (2017) a educação em saúde é um instrumento de suma importância para promoção em prevenção em todos os níveis de atenção, porém, é na ESF que se busca fortalecer o alicerce de ações, para que a população tenha uma melhoria na qualidade de vida. Ainda (Vasconcelos et al, 2017) a ESF apresenta um novo estilo de atuar em saúde, com visão para o individual e coletivo, na assistência voltada para promover, prevenir e reabilitar e no comprometimento de gerar participação popular na construção e planejamento das ações de saúde.

A educação em saúde é a principal ferramenta para a construção de uma prática de trabalho que valoriza o ser humano além do biológico, dando valor ao ser social, emocional e espiritual. O conceito e a perspectiva relatados pelas próprias enfermeiras acerca de educação em saúde, demostra também os meios pelos quais elas utilizam para a realização destas, ou seja, influenciam diretamente na escolha dos instrumentos, espaços e os métodos utilizados para educar em saúde.

\section{Temática II: As ações de educação em saúde desenvolvidas no cotidiano da ESF}

A Segunda temática trata-se das ações de educação em saúde desenvolvida no cotidiano da ESF. No relato das entrevistadas as ações educativas são realizadas em momentos variados, como no consultório durante as consultas de enfermagem, com grupos operativos de ACS e nas visitas domiciliares.

A educação em saúde é de suma importância para promoção da qualidade de vida do indivíduo. Na ESF o papel do enfermeiro é fundamental para a organização e desenvolvimento das ações. Tendo em vista as várias atribuições que estes profissionais realizam, dentre estas estão as ações educativas, que fazem destes, agentes de mudanças individuais e coletivas no contexto biopsicossocial de atenção à família (Silva et al. 2015) No relato da enfermeira ela realiza a educação em saúde no consultório durante as consultas de enfermagem.

“Assim, sempre nas consultas, eu faço as orientações aos pacientes, então dali eu já to trabalhando educação em saúde. (...) já tô ensinado né? no corredor, então lá no consultório mesmo" (Enf. 2)

A Consulta de enfermagem é um momento individual, onde o paciente pode expor seu problema de saúde, suas dúvidas e anseios. E neste momento o profissional e o cliente estabelecem um vínculo de confiança. Que facilita a abordagem unificada e direcionada ao assunto do qual o cliente necessita e que poderia hesitar em falar ou questionar em público. 


\section{ORANGE JOURNAL}

Outro ponto importante é a ação educativa com os grupos operativos. Que é compreendido como um conjunto de pessoas que possuem problemas em comum, e que se reúnem para trocar conhecimentos e experiências e também adquirir novas habilidades de superação, na busca por melhor qualidade de vida (Antunes 2015; Mazzuchello et al, 2014).

Podemos observar na fala da entrevistada, que a mesma realiza educação em saúde com os grupos operativos.

"Eu trabalho mais dois grupos fortes, que eu tenho, que é os hipertensos e diabéticos e as gestantes. Então a gente trabalha geralmente mais esses dois grupos. Daí a gente ensina várias coisas, faz educação com eles" (Enf. 2)

Segundo os mesmos autores (Mazzuchello et al, 2014), as práticas educativas na modalidade grupal, possibilita aos participantes empoderamento de conhecimentos, discussões, críticas e construção de técnicas saudáveis alusivas as ações de saúde, tendo em vista que é no grupo que as pessoas enfrentam suas limitações de maneira mais adequada e assim também resgatam sua autonomia para viver num estilo mais condizente com suas condições de saúde.

Observa-se que as atividades educativas com grupos operativos são realizadas. A enfermeira relata que trabalha com dois grupos fortes, os hipertensos e diabéticos e as gestantes. Acredita-se que estes são mais atuantes devido estarem vinculados aos programas hiperdia e saúde da mulher.

A gestante porque precisa do acompanhamento do pré-natal, imunização, solicitação de exame tem mais essa responsabilidade de cuidar da saúde e os hipertensos e diabéticos as consultas, orientações, fornecimento de medicamentos, controle da glicemia e pressão arterial e novos hábitos alimentares. Portanto o papel do enfermeiro como educador é fundamental para o desenvolvimento das atividades em grupo, gera vinculo de confiança, e isso faz com que os usuários busquem conhecimento, esclarecimentos e melhor qualidade de vida.

Também são realizadas educação em saúde com os ACS. Dentre as atribuições específicas do enfermeiro estão: supervisionar, coordenar e realizar as atividades de educação permanente dos ACS e da equipe de enfermagem. Logo, este profissional se depara a todo o momento com situações concretas referentes à educação, não somente com a comunidade, mas também com capacitação dos profissionais sob sua supervisão (Bassoto e Radicchi, 2012).

Como observado na fala da enfermeira:

"Com os agentes de saúde, eu costumo fazer também educação em saúde. A gente senta, nas reuniões a gente conversa, debate sobre algum assunto. (...) A gente discute sobre alguma, algum tema" (Enf. 3) 
Nota-se que a enfermeira realiza as atividades de educação permanente com ACS através de reuniões, debates e discussão sobre algum tema importante. Com relação ao tema a serem discutidos nas reuniões, que os mesmos sejam propostos pelos ACS, pois estes estão em contato constante com a população, e possuem maior conhecimento da comunidade e, consequentemente de suas necessidades. E posteriormente esses agentes repassaram aos usuários o que aprenderam com os temas discutidos.

Portanto, a identificação das necessidades educativas por meio do trabalho multiprofissional é mais efetiva, pois não parte apenas da observação de uma única pessoa, mas sim de toda uma equipe que conhece e convive com a população (Roecker, Budó, e Marcon, 2012). E assim gera novas competências ao trabalho deste grupo, somando novos conhecimentos e fortalecendo as experiências, para que juntamente possam enfrentar os desafios, permitindo a população uma melhor qualidade de vida (Bassoto e Radicchi, 2012).

A ação educativa é um dos principais eixos norteadores das ações do enfermeiro, e se concretiza nos vários espaços de realização das práticas de enfermagem em geral (Acioli, 2008). Deste modo, o enfermeiro pode buscar espaços diversificados para promovê-la. Visando alcançar a sua clientela adscrita e consequentemente promover educação em saúde.

$\mathrm{Na}$ fala das enfermeiras as ações educativas também são realizadas fora dos muros da instituição. Como observado nas falas:

"A gente trabalha, mas não dentro da unidade, mas sim fora, como nas escolas, as vezes nas igrejas, porque o ESF seria isso, trabalhar educação em saúde, sempre! (...) nós temos o quilombo e temos duas escolas. Então geralmente a gente coloca, ou a gente vai para o quilombo pra fazer atividades lá ou nas escolas, geralmente uma vez por mês a gente sai para fazer fora" (Enf. 1)

"Então, a gente trabalha da seguinte forma, eu gosto muito de trabalhar com ações. Ações na comunidade, onde a gente leva é, panfletos, a gente leva, é que acadêmicos também que ajudam muito, e os próprios profissionais. É orientando a população, sobre é, prevenção de doenças (...) aquela população que tá mais provável ter doenças diarreicas, malária, doenças endêmicas. Então a gente leva, eu costumo mais fazer ações comunitárias, pra levar até essas pessoas. É educação em saúde” (Enf. 3)

Os profissionais entrevistados reconhecem a necessidade de realizar atividades para além dos muros da instituição, principalmente porque precisam levar educação em saúde para um público que nem sempre comparece a unidade. Desta maneira realizam ações educativas em escolas, associações e outras.

Conforme (Oliveira e Gonçalves, 2004; Sousa, Brandão, e Parente, 2015) consideram que não existem limites e fronteiras para a realização da educação em saúde, podendo ser desenvolvida fora da unidade ou extramuros, que acaba por romper as barreiras físicas e de acesso, necessitando ampliar a participação social e consequentemente promover a autonomia do auto cuidado. 


\section{ORANGE JOURNAL}

Outro instrumento utilizado como estratégia de educação em saúde é a visita domiciliar, uma ferramenta muito importante porque possibilita o vínculo e ações de promoção de saúde no contexto onde a família está inserida. Conforme o relato das enfermeiras elas realizam as visitas domiciliares:

"Semanalmente nas visitas domiciliares. A gente vai faz as visitas, e daí a gente já tá, ali levando a educação pra eles, pros pacientes" (Enf. 2)

"Até mesmo em casa com as orientações quando vamos fazer as nossas visitas domiciliares, né?" (Enf. 4)

É importante que as visitas domiciliares sejam realizadas, assim o profissional se aproxima da população, criando vínculo afetivo, gerando confiança. Dessa forma, a população sente-se à vontade e então partilha suas dificuldades, angústias, medos para que estes possam ser superados (Batista, Farias, e Melo, 2013). Nota-se que as ações educativas podem instrumentalizar indivíduos e grupos na construção de conhecimento e meios de melhor lidar com o processo saúde e doença.

A Lei $\mathrm{n}^{\circ} 10.424$, de 15 de abril de 2002, que acrescenta capítulo e artigo à Lei $\mathrm{n}^{\circ} 8.080$ / 1990, (Lei No 10.424, 2002) regulamentando a assistência domiciliar no Sistema Único de Saúde (SUS). Conselho Federal de Enfermagem, por meio da Resolução No 0464/2014 (Conselho Federal de Enfermagem, entende por atenção domiciliar de enfermagem "as ações desenvolvidas no domicílio da pessoa, que visem à promoção de sua saúde, à prevenção de agravos e tratamento de doenças, bem como à sua reabilitação e nos cuidados". Considera ainda, o atendimento domiciliar, o conjunto de ações educativas ou assistenciais que o paciente ou familiar recebe em sua residência por profissionais de enfermagem ( Resolução Cofen No 0464/2014).

Nos relatos é possível notar que as enfermeiras se utilizam de estratégias diversificadas para promover educação em saúde, seja durante a consulta de enfermagem, na entrega de panfletos, ou ainda estendendo suas ações para além dos muros da unidade. Isso mostra a necessidade de adequar as ações de acordo com a realidade das instituições que apresentam algumas dificuldades e limitações para a realização das ações planejadas.

\section{Temática III - Fatores que dificultam a realização da educação em saúde}

A terceira temática está relacionada aos fatores que dificultam a realização da educação em saúde. Relatadas pelas enfermeiras estão: Espaço físico, desinteresse da população, transporte, carência de materiais, demanda e as questões burocráticas.

Durante as visitas realizadas nas unidades de saúde, para a realização das entrevistas, pode-se observar que não há um auditório, ou mesmo um espaço físico adequado para se realizar as atividades educativas. $\mathrm{O}$ que dificulta de certo modo a execução das atividades. A falta de espaço impede que sejam desenvolvidas as atividades educativas, segundo o relato da enfermeira. 
“(...) não tem como a gente trabalhar. Por que? As salas são pequenas, a gente não tem um lugar reservado, (...) isso aí influi e muito a gente trabalhar realmente educação em saúde" (Enf.1)

A UBS tem que dispor de um espaço amplo, confortável e no conceito de ambiência na saúde deve ser um espaço que proporcione conforto, bem estar, privacidade, atendimento humanizado que seja acolhedor e resolutivo tanto para usuários, trabalhadores e profissionais de saúde. De acordo com (Brazil, Secretaria de Atenção à Saúde, e Núcleo Técnico da Política Nacional de Humanização, 2009) "tratamento dado ao espaço físico entendido como espaço social, profissional e de relações interpessoais que deve proporcionar atenção acolhedora, resolutiva e humana".

Entre as dificuldades relatadas pelas enfermeiras estão relacionadas à falta de transporte, bem como, de materiais adequados que chame a atenção da população sobre o assunto abordado. As mesmas precisam de um veículo pois algumas áreas de abrangência são extensas e acabam dificultando o acesso da equipe, e pela necessidade de transportar materiais que servirão de apoio para que suas ações tenham êxito. Conforme o relato das entrevistadas:

"Umas das dificuldades, umas das principais dificuldades que eu vejo. Tipo, a minha área é uma área extensa, né? Daí a gente. A dificuldade que eu tenho é a de transporte. Porque se, se eu for pra, pra algum local, eu tenho que levar algum material. Né? Que vai chamar atenção, não adianta as vezes a chegar só a gente lá com a equipe. Aí não vai chamar a atenção do usuário. Aí você tem que levar o material pra ele. Você tem que. Se tivesse pelo menos mais estrutura. Tipo um datashow, uma coisa assim que eu pudesse levar" (Enf.2).

"Dificuldades, assim, as vezes, é (pensando), locomoção né, para levar os materiais, as vezes é, é um pouco complicado (...)” (Enf. 3)

"Bom a gente, a gente tem muitas dificuldades (...) com nossos matérias, que as vezes a gente não consegue né? reunir todos, nós fazemos uma programação. Dentro dessa programação você tem um custo né? É você tem uns, algumas coisas que você utiliza. Então geralmente a gente solicita pra Secretária de Saúde, mas a gente não recebe todo esse material, como deveríamos. Então a dificuldade pra realizar é essa, é, carência de matérias que as vezes pode. A gente tira até mesmo do nosso bolso, pra poder fazer acontecer, pra não deixar é as nossas programações, é deixar de ser realizadas. Entendeu? então é isso." (Enf. 4)

Essas dificuldades acabam limitando as ações educativas em saúde, principalmente a insuficiência de materiais, que são igualmente responsáveis por obstar o trabalho educativo. Para que as ações sejam desenvolvidas algumas vezes há necessidade das enfermeiras investirem recurso financeiro próprio, tendo em vista que não são atendidas pela Secretaria de Saúde as solicitações realizadas por elas dos materiais necessários.

No estudo realizado por Roecker, Budó e Marcon (2012) a respeito das dificuldades e perspectiva dos enfermeiros acerca do desenvolvimento das ações educativas, aponta que 


\section{ORANGE JOURNAL}

as principais dificuldades encontradas são a falta de recursos físicos, matérias e financeiro. E justifica que para o desenvolvimento das ações é necessário ter um espaço físico adequado, bem como um transporte em boas condições. As dificuldades descritas nas entrevistas realizadas se assemelham as apontadas em outros estudos que pesquisam está temática, onde os principais fatores que limitam a realização das ações educativas incluem a precariedade da estrutura física das instituições e a falta de recursos materiais (Marcon, Lopes, e Lopes, 2008).

Outro ponto importante exposto pelas enfermeiras é o "desinteresse da população" em participar das atividades educativas, mesmo que havendo convite e divulgação ainda assim não comparecem. A demanda alta durante as consultas de enfermagem também acaba dificultando o desenvolvimento das ações, bem como pelas questões burocráticas que são de responsabilidades da enfermeira. Como analisado na fala das enfermeiras:

"A gente tem a informação pra levar pra nossa população, mas também muitas das vezes a nossa população não vai ao nosso encontro" (Enf. 1)

“(...) então até mesmo a questão, toda vez que a gente convida a comunidade eles tipo eles vão participar lá, mas depois tem que ter um lanchinho, alguma coisa pra que eu possa, rs rs rs, oferecer pra eles. As vezes não tem. Então isso já não chama atenção. Eles, eles ficam mais. É tipo, o foco deles mais é tipo querer consulta, consulta, medicação e pronto. Entendeu? Dentro da, da unidade. Ha! eu creio que a nossa rotina atrapalha. Porque, a demanda é alta pra atender (...). Além da, da demanda, eu tenho a questão burocrática, entendeu? Que também pesa. Tem que fazer, ai acaba tomando todo tempo. Aí acaba ficando sem tempo pra, pra fazer uma coisa que é bem importante que eu gosto que é educação em saúde." (Enf 2)

\section{“Às vezes até a resistência mesmo da população" (Enf. 3)}

Fica evidenciado na fala da enfermeira que os usuários procuram a unidade de saúde para atendimento curativista, a maior parte das pessoas que procuram o atendimento na instituição visam os cuidados direcionados a alguma patologia, que resultam a maioria das vezes em receber um tratamento farmacológico. Além disto, a comunidade não está habituada e não foi preparada para participar de ações que visam prevenir agravos, que acaba contribuindo com o desinteresse em participar das ações educativas.

(Budó e Saupe, 2004; Roecker et al, 2012) consideram que entre os entraves para o desenvolvimento da educação em saúde estão: falta de aceitação e adesão às atividades educativas, no que diz respeito ao interesse dos usuários, bem como a cultura curativa valorizada por eles. (Sberse e Claus, 2003) apontam que a prescrição de medicamentos é vista pelos pacientes como a alternativa principal no que diz respeito aos cuidados prestados a saúde e não enxergam na educação em saúde uma forma de melhorar a qualidade de vida.

(Jesus et al, 2008) investigou em seu estudo os fatores que interferem no desenvolvimento da prática de educação em saúde, concluindo que a grande demanda do serviço e o excesso de atividades burocráticas, aliadas a falta de estrutura física, falta de 
investimentos em matérias, são fatores que dificultam o desenvolvimento das práticas educativas.

Analisando as atribuições do enfermeiro dentro da ESF é possível compreender nos discursos, a relação das dificuldades encontradas para educar em saúde quando relacionadas ao serviço burocrático desempenhado por essas profissionais. Essas atividades exigem tempo e disponibilidade para desenvolvê-las, e o enfermeiro precisa desdobrar-se para educar em saúde, prestar assistência e gerenciar o serviço.

\section{Conclusão}

Conclui-se que os objetivos traçados para esta pesquisa foram alcançados. Observou-se que as enfermeiras da ESF possuem entendimento acerca da concepção de educação em saúde. Nos relatos elas apontam como uma importante ferramenta de prevenção e que através deste instrumento pode-se conscientizar, orientar a população sobre doenças e agravos. Bem como, conscientizar as pessoas de suas responsabilidades em relação à sua vida, fortalecendo, dessa forma a autonomia de cada indivíduo.

Quanto ao trabalho de educação em saúde, estes são realizados em momentos diferentes, ou seja, dentro da unidade de saúde durante as consultas de enfermagem onde se tem uma abordagem mais individualizada e em outro momento com grupos operativos, que abrange um número mais elevado de participantes, as atividades em grupo faz com que as pessoas enfrentem suas limitações, anseios, dúvidas. E desta forma o enfermeiro contribui para o fortalecimento da autonomia do sujeito em cuidar da própria saúde.

O enfermeiro realiza ainda por meio de encontros e reuniões as capacitações dos ACS, com o intuito de prepará-los para educar em saúde durante as visitas domiciliares realizadas por esses profissionais, tendo em vista que estes mantêm um contanto mais próximo com a população adscrita. As ações extramuros visam levar educação em saúde para as pessoas que não comparecem na unidade. A utilização dessas ações, demonstra o interesse e a preocupação das enfermeiras em promover atividades educativas que alcance um número maior de participantes. Desta maneira utilizam-se de estratégias como, palestras em escolas, em associações, com grupos específicos, entre outros. No entanto essas atividades e ações planejadas nem sempre são executadas da maneira desejada. Sendo que em certas ocasiões não se consegue atingir o público alvo, por motivos variados, seja por desinteresse da população em participar, em alguns casos, não reconhecem a educação em saúde como estratégia para cuidar da saúde. Ou ainda, por estar habituado ao modelo curativista.

Outro fator dificultador para a realização das ações, pode estar relacionado ao despreparo da equipe para traçar estratégias apropriadas ao público em questão. Sabe-se que as dificuldades financeiras, de recursos didáticos, de infraestrutura inadequada, também contribuem de forma negativa para que as ações não sejam planejadas e executadas adequadamente.

Embora com as dificuldades descritas é possível concluir que as ações de educação em saúde nas ESF acontecem. As enfermeiras utilizam dos recursos disponíveis e das 


\section{ORANGE JOURNAL}

oportunidades que surgem para realizar as suas atividades. Executadas durante algumas programações e incentivando os acadêmicos e/ou estagiários a participarem na realização das mesmas.

Espera-se que este estudo contribua para o fortalecimento das ações educativas em saúde, através da valorização destas, como instrumento de prevenção e promoção da saúde, bem como da autonomia dos indivíduos envolvidos neste processo. Contribua também para despertar o interesse por essa temática por parte dos acadêmicos da área da saúde e dos profissionais que atuam na área, tendo em vista a grande relevância e a necessidade de discutir a educação em saúde sobre uma nova perspectiva.

\section{Referencias}

Acioli, S. (2008). A prática educativa como expressão do cuidado em Saúde Pública. Revista Brasileira de Enfermagem, 61(1), 117-21. Doi: 10.1590/S003471672008000100019.

Antunes, L. (2015). Universidade Federal de Minas Gerais Escola de Enfermagem. 26.

Bardin, L. (2016). Análise de conteúdo. 70o ed. Lisboa: Almedina.

Bardin, L., Reto, L.A., e Pinheiro, A. (2000). Análise de conteúdo. Lisboa: Edições 70.

Barra, S.A.R. (2013). Gestão da estratégia saúde da família: o desafio de consolidar a intersetorialidade, (Mestre em Serviço Social), Universidade Federal de Juiz de Fora, Brasil. 200.

Bassoto, T.R.P, e Radicchi, A.L.A. (2012). Estratégia de Saúde da Família: o papel do enfermeiro como supervisor e educador dos ACS - Biblioteca Virtual do NESCON. Recuperado 19 de janeiro de 2021 https://www.nescon.medicina.ufmg.br/biblioteca/registro/Estrategia_de_Saude_ da_Familia_o_papel_do_enfermeiro_como_supervisor_e_educador_dos_ACS/ 460

Batista, K.R.A., Farias, M.C.A.D., e Melo, W.S.N. (2013). Influência da assistência de enfermagem na prática da amamentação no puerpério imediato. Saúde em Debate, 37(96), 130-38. Doi: 10.1590/S0103-11042013000100015.

Brazil, Secretaria de Atenção à Saúde, e Núcleo Técnico da Política Nacional de Humanização. (2009). Ambiência. Brasília, D.F.: Editora MS.

Budo, MLD, e Saupe, R. (2004). Conhecimentos populares e educação em saúde na formação do enfermeiro. Revista Brasileira de Enfermagem, 57(2), 165-69. Doi: 10.1590/S0034-71672004000200007.

Cervera, D.P.P., Parreira, B.D.M., Goulart, B.F. (2011). Educação em saúde: percepção dos enfermeiros da atenção básica em Uberaba (MG). Ciência \& amp; Saúde Coletiva, 16, 1547-54. Doi: 10.1590/S1413-81232011000700090.

Horta, W. (1974). Enfermagem: teoria, conceitos, princípios e processo. Revista da Escola de Enfermagem da USP, 8, 7-17. Doi: 10.1590/00806234197400800100007.

Jesus, M.C.P., Santos, S.M.R., Amaral, A.M.M., Costa, D.M.N., Aguilar, K.S.M. (2008). O discurso do enfermeiro sobre a prática educativa no programa saúde da família em juiz de fora, minas gerais, Brasil. Revista de APS 11(1).

Lei No 10.424. Legislação Básica da Presidência da República, Brasil, Ministério da Saúde, Governo Federal, 15 de abril de 2002. Governo Federal. Recuperado 21 de fevereiro

de

2021. 
https://legislacao.presidencia.gov.br/atos/?tipo=LEI\&numero=10424\&ano=2002 \&ato=60bUTWE5ENNpWT84e.

Malta, D.C., Santos, M.A, Stopa, S.R, Vieira, J.E., Melo, E., e Reis, A.A. (2016). A Cobertura Da Estratégia de Saúde Da Família (ESF) No Brasil, Segundo a Pesquisa Nacional de Saúde, 2013. Ciência \& Saúde Coletiva, 21(2), 327-38. Doi: 10.1590/1413-81232015212.23602015.

Marcon, S.S., Lopes, M.C, e Lopes, M.B. (2008). Facilidades e dificuldades percebidas por enfermeiros na assistência à família. Online braz. j. nurs. (Online).

Mazzuchello, F., Bisognin, L., Schwalm, M., Dagostin, V., e Soratto, M. (2014). A atuação dos enfermeiros nos Grupos Operativos Terapêuticos na Estratégia Saúde da Família. O Mundo da Saúde, 38, 462-72. Doi: 10.15343/01047809.20143804462472.

Ojeda, B.S., Eidt, O.R., Canabarro, S., Corbellini, V., e Creutzberg, M. (2008). "Saberes e verdades acerca da enfermagem: discursos de alunos ingressantes". Revista Brasileira de Enfermagem, 61(1), 78-84. Doi: 10.1590/S003471672008000100012 .

Oliveira, H.M., e Gonçalves, M.J. (2004). Educação em Saúde: uma experiência transformadora. Revista Brasileira de Enfermagem, 57(6), 761-63. Doi: 10.1590/S0034-71672004000600028.

Regis, C.G., e Batista, N. (2015). O enfermeiro na área da saúde coletiva: concepções e competências. Rev Bras Enferm. 7.

Resolução Cofen No 0464/2014. Normatiza a atuação da equipe de enfermagem na atenção domiciliar. Cofen - Conselho Federal de Enfermagem, 3 de novembro de 2014. Recuperado 19 de janeiro de 2021 http://www.cofen.gov.br/resolucaocofen-no-04642014_27457.html.

Roecker, S., Budó, M.L.D., e Marcon, S.S. (2012). Trabalho educativo do enfermeiro na Estratégia Saúde da Família: dificuldades e perspectivas de mudanças. Revista da Escola de Enfermagem da USP, 46(3), 641-49. Doi: 10.1590/S008062342012000300016.

Santos, FM. (2012). Análise de conteúdo: a visão de Laurence Bardin. Revista Eletrônica de Educação, 6(1), 383-87. Doi: 10.14244/\%19827199291.

Sberse, L., e Claus, S.M. (2003). O Programa Saúde da Família na ótica de trabalhadores e usuários de saúde. Boletim de Saúde - ESP/RS, vol. 17(2). Recuperado 19 de janeiro de 2021 (http://www.boletimdasaude.rs.gov.br/conteudo/1258/oprograma-saude-da-familia-na-otica-de-trabalhadores-e-usuarios-de-saude).

Silva, J.R.A, Lemos, E.C, Hardman, C.M, Santos, S.J, \& Antunes, M.B.C. (2015). Educação em saúde na estratégia de saúde da família: percepção dos profissionais. Revista Brasileira em Promoção da Saúde 28(1), 75-81. Doi: 10.5020/18061230.2015.p75.

Sousa, M.S., Brandão, I., e Parente, J.R. (2015). A percepção dos enfermeiros SOBRE educação permanente em Saúde no contexto da estratégia Saúde da família de Sobral (CE). Revista Interfaces: Saúde, Humanas e Tecnologia 2(7). Doi: $10.16891 / 260$.

Souto, L., Freitas, M.L., Ponte, C.F., da Silva, G.M., Pulga, V.L. e Miranda, T. O. (2020). IdeiaSUS: saberes e práticas nos territórios do sistema único de saúde. Cebes.

Vasconcelos, M.I.O., Farias, Q.L.T., Nascimento, F.G., Cavalcante, A.S.P., Mira, Q.L.M., e Queiroz, M.V.O. (2017). Educação em saúde na atenção básica: uma 


\section{ORANGE JOURNAL}

análise das ações com hipertensos. Revista de APS 20(2). Doi: 10.34019/18098363.2017.v20.15943.

Villlela, L.C.M., Galastro, E.P., Freitas, M.E., Santos, M.S.G., Notaro, K.A.M. (2011). Tempo de atuação do profissional enfermeiro - Minas Gerais. Enferm. Foco (Brasília), 2(4), 248-50. 